\title{
Correlates of Bone Mineral Density and Sagittal Spinal Balance in the Aged
}

\author{
Yung Cho, $\mathrm{MD}^{1}$, Gangpyo Lee, $\mathrm{MD}^{1}$, Jhoan Aguinaldo, $\mathrm{MD}^{2}$, Kun-Jai Lee, $\mathrm{MD}^{3}$, Keewon Kim, $\mathrm{MD}^{1}$, $\mathrm{MS}^{4}$ \\ ${ }^{1}$ Department of Rehabilitation Medicine, Seoul National University College of Medicine, Seoul, Korea; \\ ${ }^{2}$ Department of Rehabilitation Medicine, University of Santo Tomas Hospital, Manila, Philippines; \\ ${ }^{3}$ Department of Rehabilitation Medicine, Kangwon National University School of Medicine, Chuncheon, Korea; \\ ${ }^{4}$ Interdisciplinary Program in Bioinformatics, Seoul National University, Seoul, Korea
}

\begin{abstract}
Objective To investigate the relationship between bone mineral density (BMD) and sagittal spinal balance in the Korean elderly population.

Methods The retrospective study included subjects aged 60 years and above, who had whole-spine lateral radiography and dual-energy X-ray absorptiometry (DEXA) within a year's gap between each other. Sagittal vertical axis (SVA) for evaluation of sagittal spinal balance and five spinopelvic parameters were measured through radiography. The presence of compression fracture was identified. Correlations of BMD T-scores with SVA and with the spinopelvic parameters were assessed using Pearson correlation coefficient (PCC). Linear regression analyses were performed between SVA and the clinical and radiologic variables.

Results One hundred twenty-two subjects (42 males and 80 females; mean age, 69.93 \pm 5.5 years) were included in the study. BMD, femur or spine, was not correlated with SVA or any spinopelvic parameters in both genders (PCC $< \pm 0.2)$, except that spine BMD in men was associated with sacral slope. Univariate regression analysis revealed association between SVA and lumbar lordosis, pelvic tilt, and compression fractures in both genders; it was also associated with age and pelvic incidence in females and with sacral slope in males. Multivariate linear regression model showed lumbar lordosis and compression fracture as variables affecting SVA in both sexes; pelvic incidence was another factor affecting SVA in women only.

Conclusion BMD was not associated with sagittal spinal balance in the aged. Sagittal spinal balance was explained partly by lumbar lordosis and compression fracture. Further study is warranted to understand progression of sagittal imbalance with age.
\end{abstract}

Keywords Bone mineral density, Sagittal spinal balance, Spinopelvic parameters

Received July 4, 2014; Accepted September 2, 2014

Corresponding author: Keewon Kim

Department of Rehabilitation Medicine, Seoul National University Hospital, 101 Daehak-ro, Jongno-gu, Seoul 110-744, Korea

Tel: +82-2-2072-2619, Fax: +82-2-743-7473, E-mail: keewonkimm.d@ gmail.com

@ This is an open-access article distributed under the terms of the Creative Commons Attribution Non-Commercial License (http://creativecommons. org/licenses/by-nc/3.0) which permits unrestricted noncommercial use, distribution, and reproduction in any medium, provided the original work is properly cited.

Copyright $\odot 2015$ by Korean Academy of Rehabilitation Medicine

\section{INTRODUCTION}

Degenerative spinal deformities, such as increased thoracic kyphosis and loss of lumbar lordosis, are common in the geriatric population. It often leads to adverse clinical consequences including functional limitations, increased risk of falls or fractures, and impaired quality of life [1-5]. 
The definition of degenerative spinal deformities is still a matter of controversy and measurement techniques are still being developed. In the past, a number of studies have been focused on localized problems: for example, disregarding the thoracic spine or the pelvis when investigating degenerative lumbar kyphosis. With accumulation of clinical observation, many physicians came to believe that global alignment of the spine was more important than local deformity $[6,7]$. Thereafter, sagittal spinal balance was conceptualized among the spinal surgeons in the 80's [6]. More recently, the importance of pelvis in the maintenance of normal sagittal balance was recognized and various pelvic parameters have been devised to assess sagittal spinal balance [6].

Decreased bone mineral density (BMD) is one of the suspected causes of degenerative hyperkyphosis and sagittal imbalance. Kyphosis can be precipitated by increasing numbers of vertebral anterior wedge fractures as BMD decreases in the aged [7]. However, a specific study reported no significant association between BMD and thoracic kyphosis [8]. Such contradictory results might reveal that sagittal spinal balance result not only from bony deformity but also from postural control [9]. Thus far, only few studies have specifically investigated the association between global sagittal spinal balance and BMD. Moreover, meager data are available on association between global sagittal spinal balance and BMD in the Korean population, although it is proven that spinopelvic curvature is strongly influenced by ethnicity [10].

In this study, we investigated the relationship between the BMD and sagittal spinal balance in the Korean elderly population including both men and women.

\section{MATERIALS AND METHODS}

\section{Subjects}

A retrospective chart review screened subjects 60 years old and above, who had a plain lateral radiography of the whole spine and DEXA (GE Healthcare Lunar Prodigy Advance, Madison, WI, USA) done within a year's gap between each other amid July 2011 and June 2013 in Seoul National University Hospital $(\mathrm{n}=219)$. Subjects with the following conditions were excluded from the study: congenital spinal deformity $(\mathrm{n}=0)$, history of vertebral infection ( $n=3)$ or trauma $(n=34)$, any malignancy $(n=29)$, previous surgery of the spine $(n=29)$, rheumatologic dis- ease $(n=2)$, problems of the central and peripheral nervous system $(n=0)$, and severe coronal imbalance with Cobb's angle $\geq 40^{\circ}(\mathrm{n}=0)$. Finally, 122 subjects ( 80 women and 42 men) were included in the study. The average age of subjects was $69.93 \pm 5.50$ years. Body mass index (BMI) was calculated from height and weight as per electronic medical record (Table 1). This study was approved by the Institutional Review Board of Seoul National University Hospital (No. H-1304 025 478).

\section{Radiologic evaluation}

Based on plain radiographs, sagittal spinal imbalance and spinopelvic parameters were measured. In terms of primary measure of global sagittal balance, SVA is defined as a horizontal distance between a plumb line dropped from the center of the C7 body and the posterior-superior corner of the S1 body [11] (Fig. 1A). When the plumb line falls in front of the posterior-superior corner of the S1 body, SVA is designated a positive value.

Five spinopelvic parameters were employed in this study: thoracic kyphosis, lumbar lordosis, pelvic incidence, pelvic tilt, and sacral slope. Thoracic kyphosis is the angle between the cranial endplate of $\mathrm{T} 4$ and the caudal endplate of T12 [12] (Fig. 1A). Lumbar lordosis is the angle between the cranial endplate of $\mathrm{Ll}$ and the caudal endplate of L5. Pelvic incidence is the angle between

Table 1. Clinical and radiological parameters of patients according to gender

\begin{tabular}{|c|c|c|c|}
\hline Parameter & $\begin{array}{l}\text { Women } \\
(\mathbf{n}=\mathbf{8 0})\end{array}$ & $\begin{array}{c}\text { Men } \\
(n=42)\end{array}$ & p-value \\
\hline Age (yr) & $69.94 \pm 5.67$ & $69.90 \pm 5.20$ & 0.975 \\
\hline $\mathrm{BMI}\left(\mathrm{kg} / \mathrm{m}^{2}\right)$ & $25.11 \pm 3.42$ & $23.76 \pm 3.47$ & $0.043^{*}$ \\
\hline Spine T-score & $-1.54 \pm 1.42$ & $-0.54 \pm 1.81$ & $0.003^{*}$ \\
\hline Femur T-score & $-1.38 \pm 0.88$ & $-0.64 \pm 0.90$ & $<0.001^{*}$ \\
\hline & 24 & 4 & \\
\hline SVA $(\mathrm{cm})$ & $4.73 \pm 4.84$ & $2.56 \pm 5.62$ & $0.028^{*}$ \\
\hline Pelvic incidence $\left({ }^{\circ}\right)$ & $60.43 \pm 11.29$ & $45.89 \pm 7.12$ & $<0.001^{*}$ \\
\hline Pelvic tilt $\left({ }^{\circ}\right)$ & $28.61 \pm 10.45$ & $16.44 \pm 8.71$ & $<0.001^{*}$ \\
\hline Sacral slope $\left({ }^{\circ}\right)$ & $31.82 \pm 9.63$ & $29.45 \pm 9.51$ & 0.197 \\
\hline Lumbar lordosis $\left({ }^{\circ}\right)$ & $25.05 \pm 17.59$ & $28.78 \pm 15.05$ & 0.246 \\
\hline Thoracic kyphosis $\left({ }^{\circ}\right)$ & $23.65 \pm 14.80$ & $36.37 \pm 9.75$ & $<0.001^{*}$ \\
\hline
\end{tabular}

Values are presented as mean \pm standard deviation or number.

BMI, body mass index; SVA, sagittal vertical axis.

${ }^{a)}$ Chi-square test. ${ }^{*} p<0.05$. 


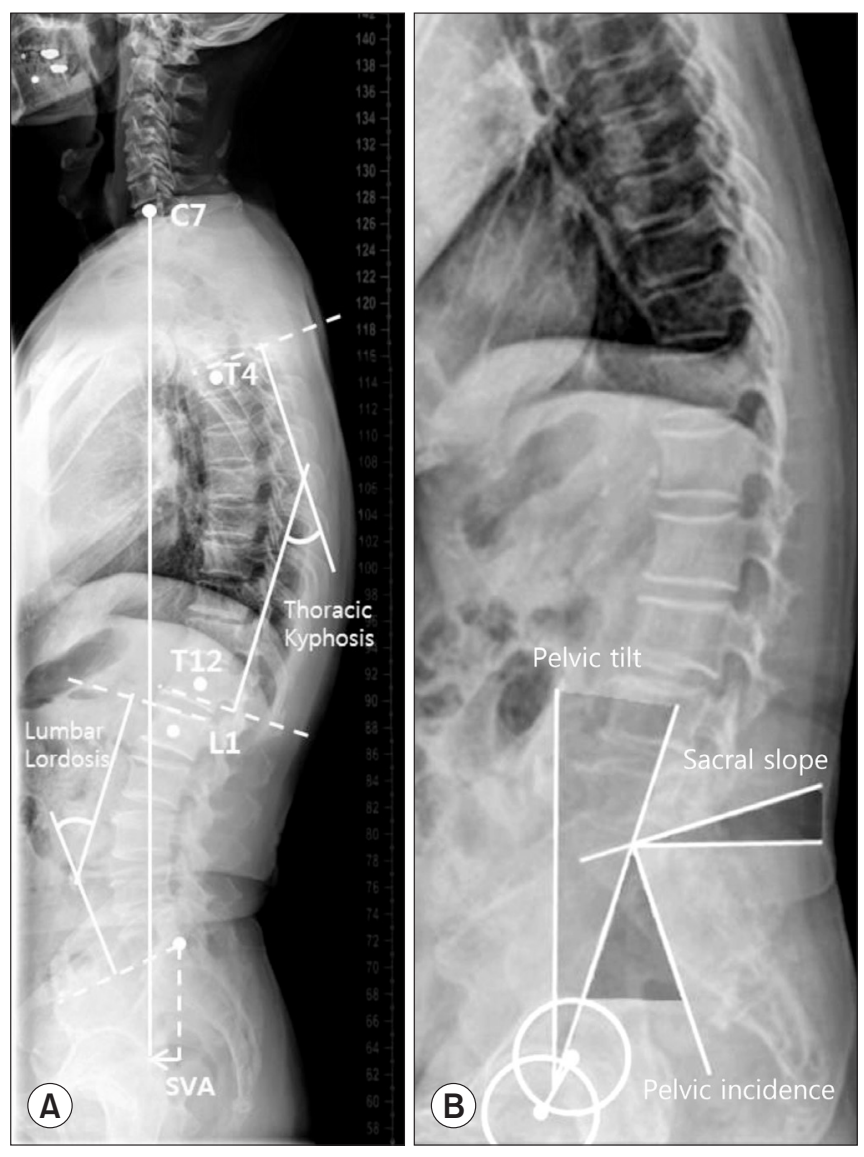

Fig. 1. (A) Methods of measurement of sagittal vertical axis (SVA) and (A, B) spinopelvic parameters are displayed.

the line perpendicular to the middle of the cranial sacral endplate and the line joining the middle of the cranial endplate to the center of the bicoxofemoral axis (the line between the geometric center of both femoral heads) [12]. Pelvic tilt is the angle between the vertical line and the line joining the middle of the sacral endplate and the center of the bicoxofemoral axis. Sacral slope is calculated by subtracting the pelvic tilt from the pelvic incidence; thus, pelvic incidence equals the sum of pelvic tilt and sacral slope [13] (Fig. 1B). All radiologic parameters were measured twice by one physician. The average of the two values was used for statistical analysis.

BMD was measured at the lumbar spine (L1-L4), femur neck, and femur total using a DEXA apparatus (GE Healthcare Lunar Prodigy Advance). BMD of lumbar spine was measured in the standard anterior-posterior projection and the results were presented as T-scores. Individual T-scores were calculated by determining the difference between the measured BMD in gram per square centimeter $\left(\mathrm{g} / \mathrm{cm}^{2}\right)$ and the mean BMD of healthy young adults matched for sex and ethnicity and dividing the difference by the standard deviation of the young adult population. In this report, lowest femur T-score and lowest spine T-score was used to denote femur BMD and spine BMD, respectively.

\section{Statistical analysis}

Correlations of BMD with sagittal spinal balance (SVA) and spinopelvic parameters were tested using Pearson correlation coefficient (PCC). Univariate linear regression analyses were used to evaluate associations of SVA with clinical (age, gender, and BMI) and radiologic variables (BMD, compression fracture, and spinopelvic parameters). Multivariate linear regression analysis was also employed to investigate the association of clinical and radiological variables with SVA. Backward elimination method was used in multivariate linear regression with elimination threshold of 0.1. All the analyses were performed separately for male and female subjects. Differences of parameters between women and men were assessed by chi-square test (for compression fracture) and independent t-test (other variables). A p-value $<0.05$ was considered statistically significant. Parametric variables were expressed with mean \pm standard deviation. The data were analyzed with Statistical Package for Social Sciences (SPSS ) ver. 18.0 (SPSS Inc., Chicago, IL, USA).

\section{RESULTS}

\section{Clinical data and radiologic parameters based on gender}

Demographic, clinical, and radiological characteristics of the participants were assessed and presented in Table 1. Females had significantly higher BMIs than males $(\mathrm{p}=0.043)$. T-scores were significantly lower in females, both at spine $(\mathrm{p}=0.003)$ and at the femur $(\mathrm{p}<0.001)$. Incidence of compression fractures were more frequent in females $(p=0.007)$. Global sagittal imbalance represented by SVA was significantly larger in women $(4.73 \pm 4.84 \mathrm{~cm})$ than in men $(2.56 \pm 5.62 \mathrm{~cm})(\mathrm{p}=0.028)$. Thoracic kyphosis was greater in males $(\mathrm{p}<0.001)$, while pelvic incidence and pelvic tilt were larger in females ( $\mathrm{p}<0.001$ for both). Lumbar lordosis and sacral slope were not significantly different between the genders. 
Correlations of BMD with SVA, and spinopelvic parameters

In women, no correlation was observed between BMD of the femur or spine with the SVA (femur: PCC $=-0.012$,

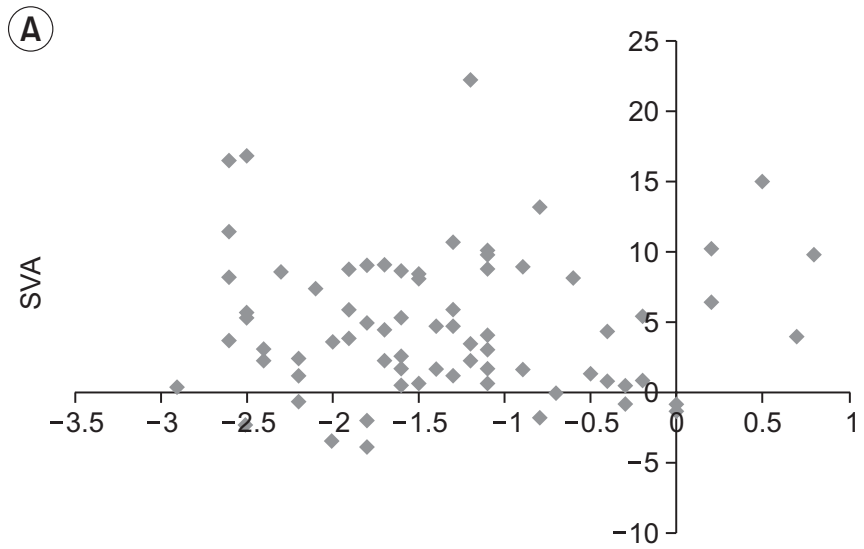

Femur T-score

(C)

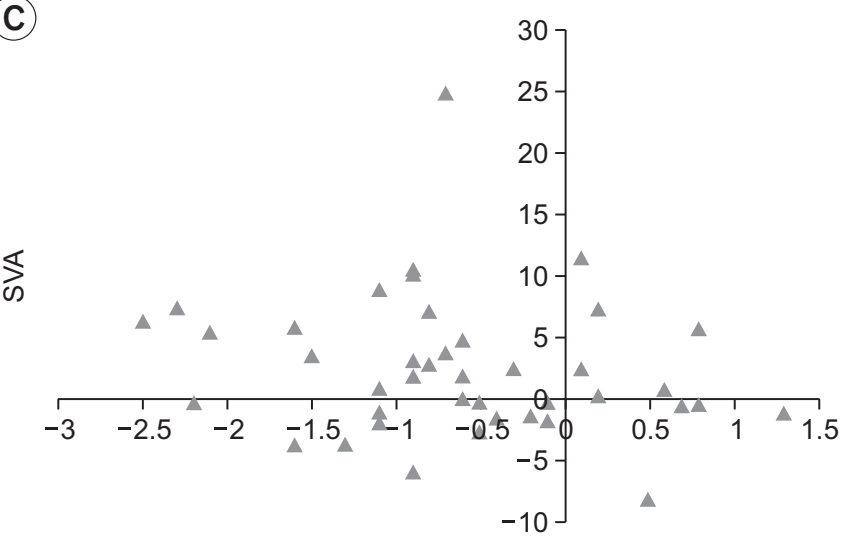

Femur T-score $\mathrm{p}=0.912$; spine: $\mathrm{PCC}=-0.001, \mathrm{p}=0.991)$ (Fig. 2A, B). In males too, BMD was not correlated with the SVA (femur: $\mathrm{PCC}=-0.179, \mathrm{p}=0.257$; spine: $\mathrm{PCC}=-0.152, \mathrm{p}=0.338$ ) (Fig. 2C, D). All the spinopelvic parameters exhibited no as-

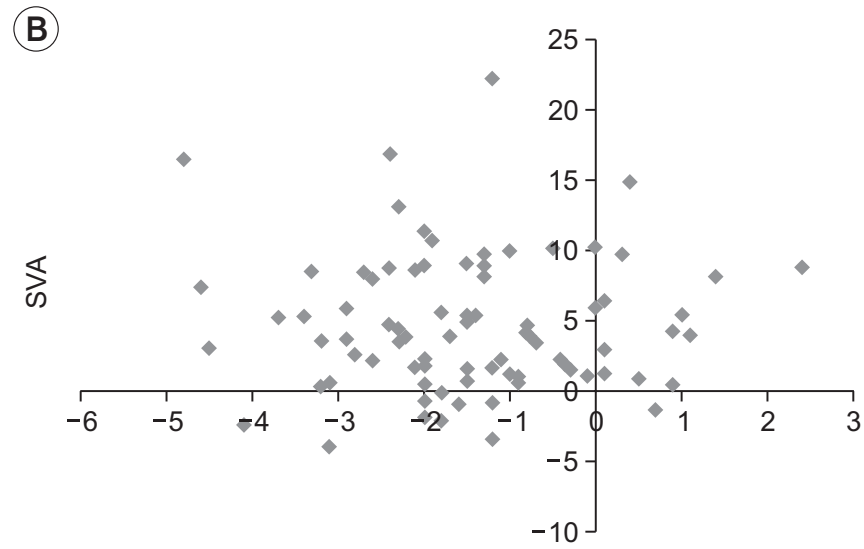

Spine T-score

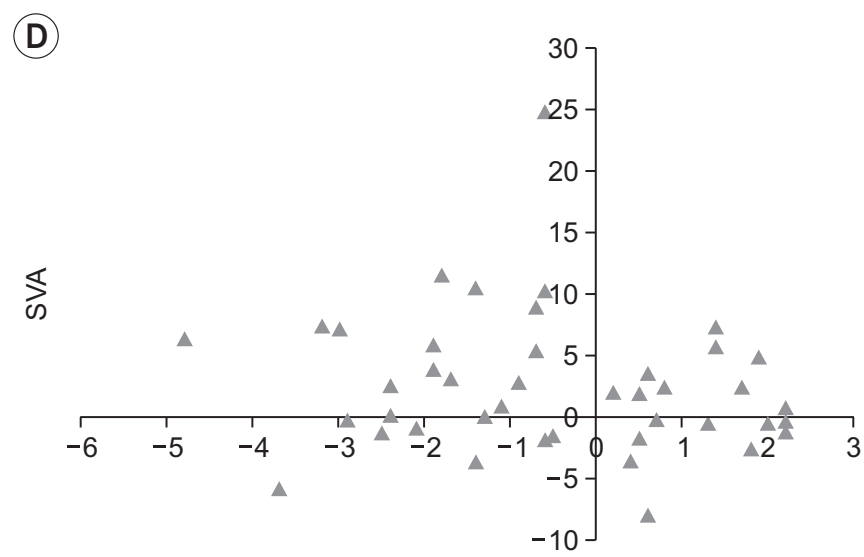

Spine T-score

Fig. 2. The scatter plot shows no correlation between bone mineral density and sagittal vertical axis (SVA) in women (A, B) and men (C, D).

Table 2. Correlations of BMD with sagittal spinal balance and spinopelvic parameters

\begin{tabular}{|c|c|c|c|c|c|c|c|c|}
\hline & \multicolumn{4}{|c|}{ Women } & \multicolumn{4}{|c|}{ Men } \\
\hline & \multicolumn{2}{|c|}{ Femur T-score } & \multicolumn{2}{|c|}{ Spine T-score } & \multicolumn{2}{|c|}{ Femur T-score } & \multicolumn{2}{|c|}{ Spine T-score } \\
\hline & PCC & p-value & PCC & p-value & PCC & p-value & PCC & p-value \\
\hline SVA & 0.012 & 0.912 & -0.001 & 0.991 & -0.179 & 0.257 & -0.152 & 0.338 \\
\hline Pelvic incidence & 0.064 & 0.575 & -0.113 & 0.316 & 0.220 & 0.161 & 0.128 & 0.420 \\
\hline Pelvic tilt & -0.047 & 0.676 & -0.200 & 0.076 & -0.046 & 0.773 & -0.256 & 0.102 \\
\hline Sacral slope & 0.126 & 0.266 & 0.084 & 0.461 & 0.207 & 0.188 & 0.330 & $0.033^{*}$ \\
\hline Lumbar lordosis & -0.070 & 0.537 & -0.014 & 0.905 & -0.122 & 0.440 & -0.216 & 0.169 \\
\hline Thoracic kyphosis & -0.205 & 0.068 & -0.111 & 0.328 & -0.194 & 0.219 & -0.238 & 0.128 \\
\hline
\end{tabular}

BMD, bone mineral density; SVA, sagittal vertical axis; PCC, Pearson correlation coefficient.

${ }^{*} \mathrm{p}<0.05$. 
Table 3. Univariate linear regression for SVA

\begin{tabular}{|lccccc}
\hline \multirow{2}{*}{ Variable } & \multicolumn{2}{c}{ Women } & & \multicolumn{2}{c}{ Men } \\
\cline { 2 - 3 } \cline { 5 - 6 } & $\boldsymbol{\beta} \pm$ SE & p-value & & $\beta \pm$ SE & p-value \\
\hline Age $(\mathrm{yr})$ & $0.236 \pm 0.093$ & $0.013^{*}$ & & $0.299 \pm 0.164$ & 0.076 \\
\hline BMI $\left(\mathrm{kg} / \mathrm{m}^{2}\right)$ & $0.146 \pm 0.160$ & 0.362 & & $0.048 \pm 0.256$ & 0.851 \\
\hline Femur T-score & $0.071 \pm 0.648$ & 0.912 & & $-1.145 \pm 0.996$ & 0.257 \\
\hline Spine T-score & $-0.004 \pm 0.382$ & 0.991 & & $-0.469 \pm 0.484$ & 0.338 \\
\hline Compression fracture & $2.889 \pm 1.117$ & $0.012^{*}$ & & $10.701 \pm 2.467$ & $<0.001^{*}$ \\
\hline Pelvic incidence $\left({ }^{\circ}\right)$ & $0.115 \pm 0.047$ & $0.017^{*}$ & & $-0.112 \pm 0.123$ & 0.371 \\
\hline Pelvic tilt $\left({ }^{\circ}\right)$ & $0.155 \pm 0.049$ & $0.002^{*}$ & & $0.231 \pm 0.095$ & $0.020^{*}$ \\
\hline Sacral slope $\left({ }^{\circ}\right)$ & $-0.026 \pm 0.057$ & 0.651 & & $-0.257 \pm 0.084$ & $0.004^{*}$ \\
\hline Lumbar lordosis $\left({ }^{\circ}\right)$ & $-0.096 \pm 0.029$ & $0.002^{*}$ & & $-0.238 \pm 0.045$ & $<0.001^{*}$ \\
\hline Thoracic kyphosis $\left({ }^{\circ}\right)$ & $0.024 \pm 0.037$ & 0.520 & & $-0.079 \pm 0.091$ & 0.388 \\
\hline
\end{tabular}

SVA, sagittal vertical axis; BMI, body mass index; SE, standard error.

${ }^{*} \mathrm{p}<0.05$.

Table 4. Multivariate linear regression analysis for spinal balance

\begin{tabular}{|c|c|c|c|c|}
\hline \multirow{2}{*}{ Variable } & \multicolumn{2}{|c|}{ Women } & \multicolumn{2}{|c|}{ Men } \\
\hline & $\beta \pm S E$ & p-value & $\beta \pm S E$ & p-value \\
\hline Lumbar lordosis $\left(^{\circ}\right)$ & $-0.103 \pm 0.028$ & $0.001^{*}$ & $-0.176 \pm 0.050$ & $0.001^{*}$ \\
\hline Pelvic incidence $\left(^{\circ}\right)$ & $0.148 \pm 0.043$ & $0.001^{*}$ & - & - \\
\hline Compression fracture & $1.905 \pm 1.038$ & 0.070 & $6.194 \pm 2.515$ & $0.018^{*}$ \\
\hline
\end{tabular}

SE, standard error.

${ }^{*} \mathrm{p}<0.05$.

sociation with BMD except for the sacral slope in men; sacral slope in men showed positive correlation with spine T-score (PCC $=0.330, \mathrm{p}=0.033$ ) (Table 2).

\section{Associations between SVA and clinical/radiological variables}

Univariate linear regression analysis showed association between SVA and compression fractures, lumbar lordosis, and pelvic tilt in both the genders. In women, association between age and pelvic incidence was noted; another factor in men was sacral slope. Neither spine nor femur T-score exhibited correlation with SVA in both males and females (Table 3).

Multiple linear regression analysis was performed with variables selected from the univariate analyses. Lumbar lordosis, pelvic incidence, and compression fracture in women were the explaining parameters for sagittal imbalance; a decrease in lumbar lordosis and an increase in pelvic incidence, and presence of compression fracture were associated with worse sagittal imbalance (increase in SVA). Compression fracture was included in the multivariate regression model, but statistical significance was equivocal $(\mathrm{p}=0.07)$. In men, lumbar lordosis and compression fracture were the significant contributing factors to sagittal imbalance; as lumbar lordosis decreased and compression fracture was accompanied, sagittal imbalance increased (Table 4).

\section{DISCUSSION}

Abnormal curvature of the spine in the sagittal plane has been documented to cause significant impairments in the aged $[4,14]$. Previous studies revealed that the sagittal alignment is influenced by multi-factors, such as age, sex, weight, pelvic morphology, and history of spinal fusion $[15,16]$. However, little is known about the contribution of decreased BMD to sagittal spinal imbalance. In the present study, no association between sagittal spinal balance and BMD was noted.

Previous studies of sagittal spinal balance have report- 
ed conflicting results about its association with BMD. Lee et al. [17] showed that femur neck BMD and pelvic incidence contributed significantly to sagittal balance. However, the study population included only patients with osteoporosis; it did not consider subjects with osteopenia or with normal BMD. In addition, they did not explain why the sagittal balance was not associated with the BMD of the spine, which was supposed to have more direct impact on it.

On the other hand, Mika et al. [8] reported that the degree of thoracic kyphosis in the aged female was not different among the groups with osteoporosis, osteopenia, and normal BMD. They also showed that, in multivariate analysis, BMD did not significantly influence thoracic kyphosis. Nevertheless, the study was focused only on thoracic kyphosis, and not on global sagittal balance. Our current study included subjects with wide range of BMD (normal, osteopenia, and osteoporosis) and no correlation with BMD and sagittal balance was observed. In association with previous studies and our current study, we infer that decrease in BMD by itself does not contribute to the progression of sagittal imbalance in the aged population. Rather, BMD and sagittal imbalance might have common confounding factors.

It is noteworthy that the presence of vertebral compression fracture influenced sagittal balance in both males and females based on multivariate regression (although no statistical significance was observed in case of females). This result is consistent with previous studies reporting that a minor part of sagittal imbalance was due to structural deformities $[18,19]$. Despite the association between sagittal balance and the presence of compression fractures, SVA was not correlated with BMD. Compression fractures might be a cause as well as a result of the sagittal imbalance in the aged. Furthermore, sagittal imbalance may be influenced by other factors, which are associated with compression fracture and not with BMD in the aged persons, such as back muscle weakness, ligament degeneration, sensory deficits, or loss of motor coordination. The risk of development of compression fracture is higher in the presence of osteoporosis. However, the incidence of compression fracture is affected by various factors other than BMD, like increased stress loading from exacerbation of kyphosis [20]; and reduced strength of the back extensor in the aged, which leads to senile kyphosis that subsequently prompts the develop- ment of compression fractures.

In both univariate and multivariate regression analyses, lumbar lordosis angle was seen to have a negative correlation with global sagittal imbalance in both the genders. This result is consistent with previous literature, which stated that a loss in lumbar lordosis might be an initiating event for sagittal imbalance [13]. Therefore, decreased lordosis itself can be considered as an indicator of sagittal imbalance. In this study, we included lumbar lordosis as an explaining factor because it could contribute progression of sagittal imbalance structurally.

In the present study, SVA, thoracic kyphosis, pelvic incidence, and pelvic tilt were all significantly different between both the genders. These findings, specifically that for pelvic incidence, are inconsistent with evidence seen from previous literatures [21,22]. Since women's SVA was significantly larger than men's, it may consequently mean that the proportion of imbalanced subjects in women was also higher. This difference in sagittal imbalance between men and women may account for the difference in pelvic incidence, which is consistent with findings from a study by Lee et al. [17], which states that pelvic incidence was higher in cases with worse sagittal imbalance.

Age was one of the statistically significant factors in women in the univariate analysis. This observation is consistent with the findings of the study by Takeda et al. [23], which showed a significant correlation between age and SVA. However, in the multivariate analysis, age did not influence SVA upon adjustment for other variables; this means that age does not directly affect sagittal imbalance. Because regression analysis depends on study population, further research with larger population would be helpful to confirm the contribution of age.

There are a few limitations in this study. First, the position during obtaining the whole-spine radiography was not consistent between subjects and this factor could not be addressed appropriately because of the retrospective nature of the present study. Moreover, the angle of arm forward flexion could shift the SVA [24]. However, most of the plain radiographs of the whole spine in this study were performed with the arm forward flexion to about $45^{\circ}$. In addition, compensatory knee flexion may mask a severe spinal deformity without fully extended knee position [25]. Second, the number of subjects was limited, especially the number of male subjects with low BMD compared to those with normal BMD. It was inevitable 
because much fewer men than women, in general population, develop very low levels of BMD [26]. Third, SVA was the only method used for evaluating global sagittal balance in this study. Several other ways of assessing sagittal balance have been proposed recently. Barrey et al. [27] suggested the use of angular and/or ratio parameters (spino-sacral angle and/or C7 plumb line/sacro-femoral distance ratio, respectively) rather than employing linear distance measure. Further study using these parameters would corroborate findings of this study. Lastly, the study was retrospective design and the subjects were limited to only those, who visited the hospital. Some of them visited the hospital for routine check-up; however, there were some patients who had various conditions in the spine. Different diagnoses of such patients could have affected the results of the study. For the inclusion of general population, community based cohort study will warrant this study results.

In conclusion, the present study is the first study of its kind to show that BMD was not associated with sagittal spinal balance not only in the aged women, but also in the aged men. Lumbar lordosis and presence of compression fracture had partial effect on sagittal spinal balance. Further prospective study is warranted to understand progression in sagittal imbalance with age.

\section{CONFLICT OF INTEREST}

No potential conflict of interest relevant to this article was reported.

\section{REFERENCES}

1. Kado DM, Prenovost K, Crandall C. Narrative review: hyperkyphosis in older persons. Ann Intern Med 2007; 147:330-8.

2. Leech JA, Dulberg C, Kellie S, Pattee L, Gay J. Relationship of lung function to severity of osteoporosis in women. Am Rev Respir Dis 1990;141:68-71.

3. Kado DM, Lui LY, Ensrud KE, Fink HA, Karlamangla AS, Cummings SR, et al. Hyperkyphosis predicts mortality independent of vertebral osteoporosis in older women. Ann Intern Med 2009;150:681-7.

4. Martin AR, Sornay-Rendu E, Chandler JM, Duboeuf F, Girman CJ, Delmas PD. The impact of osteoporosis on quality-of-life: the OFELY cohort. Bone 2002;31:32-6.
5. Imagama S, Ito Z, Wakao N, Seki T, Hirano K, Muramoto A, et al. Influence of spinal sagittal alignment, body balance, muscle strength, and physical ability on falling of middle-aged and elderly males. Eur Spine J 2013;22:1346-53.

6. Johnson RD, Valore A, Villaminar A, Comisso M, Balsano M. Sagittal balance and pelvic parameters: a paradigm shift in spinal surgery. J Clin Neurosci 2013; 20:191-6.

7. Katzman WB, Wanek L, Shepherd JA, Sellmeyer DE. Age-related hyperkyphosis: its causes, consequences, and management. J Orthop Sports Phys Ther 2010;40:352-60.

8. Mika A, Unnithan VB, Mika P. Differences in thoracic kyphosis and in back muscle strength in women with bone loss due to osteoporosis. Spine (Phila Pa 1976) 2005;30:241-6.

9. Cutler WB, Friedmann E, Genovese-Stone E. Prevalence of kyphosis in a healthy sample of pre- and postmenopausal women. Am J Phys Med Rehabil 1993;72:219-25.

10. Zarate-Kalfopulos B, Romero-Vargas S, Otero-Camara E, Correa VC, Reyes-Sanchez A. Differences in pelvic parameters among Mexican, Caucasian, and Asian populations. J Neurosurg Spine 2012;16:516-9.

11. Jackson RP, McManus AC. Radiographic analysis of sagittal plane alignment and balance in standing volunteers and patients with low back pain matched for age, sex, and size: a prospective controlled clinical study. Spine (Phila Pa 1976) 1994;19:1611-8.

12. Vialle R, Levassor N, Rillardon L, Templier A, Skalli W, Guigui P. Radiographic analysis of the sagittal alignment and balance of the spine in asymptomatic subjects. J Bone Joint Surg Am 2005;87:260-7.

13. Le Huec JC, Charosky S, Barrey C, Rigal J, Aunoble S. Sagittal imbalance cascade for simple degenerative spine and consequences: algorithm of decision for appropriate treatment. Eur Spine J 2011;20 Suppl 5:699-703.

14. Nevitt MC, Ettinger B, Black DM, Stone K, Jamal SA, Ensrud K, et al. The association of radiographically detected vertebral fractures with back pain and function: a prospective study. Ann Intern Med 1998;128:793-800.

15. Gelb DE, Lenke LG, Bridwell KH, Blanke K, McEnery KW. An analysis of sagittal spinal alignment in 100 as- 
ymptomatic middle and older aged volunteers. Spine (Phila Pa 1976) 1995;20:1351-8.

16. Jackson RP, Kanemura T, Kawakami N, Hales C. Lumbopelvic lordosis and pelvic balance on repeated standing lateral radiographs of adult volunteers and untreated patients with constant low back pain. Spine (Phila Pa 1976) 2000;25:575-86.

17. Lee JS, Lee HS, Shin JK, Goh TS, Son SM. Prediction of sagittal balance in patients with osteoporosis using spinopelvic parameters. Eur Spine J 2013;22:1053-8.

18. Kado DM, Browner WS, Palermo L, Nevitt MC, Genant HK, Cummings SR. Vertebral fractures and mortality in older women: a prospective study. Study of Osteoporotic Fractures Research Group. Arch Intern Med 1999;159:1215-20.

19. Schneider DL, von Muhlen D, Barrett-Connor E, Sartoris DJ. Kyphosis does not equal vertebral fractures: the Rancho Bernardo study. J Rheumatol 2004;31:74752.

20. De Smet AA, Robinson RG, Johnson BE, Lukert BP. Spinal compression fractures in osteoporotic women: patterns and relationship to hyperkyphosis. Radiology 1988;166:497-500.

21. Jentzsch T, Geiger J, Bouaicha S, Slankamenac K, Nguyen-Kim TD, Werner CM. Increased pelvic incidence may lead to arthritis and sagittal orientation of the facet joints at the lower lumbar spine. BMC Med Imaging 2013;13:34.

22. Mac-Thiong JM, Roussouly P, Berthonnaud E, Guigui P. Age- and sex-related variations in sagittal sacropelvic morphology and balance in asymptomatic adults. Eur Spine J 2011;20 Suppl 5:572-7.

23. Takeda N, Kobayashi T, Atsuta Y, Matsuno T, Shirado $\mathrm{O}$, Minami A. Changes in the sagittal spinal alignment of the elderly without vertebral fractures: a minimum 10-year longitudinal study. J Orthop Sci 2009;14:74853.

24. Vedantam R, Lenke LG, Bridwell KH, Linville DL, Blanke $\mathrm{K}$. The effect of variation in arm position on sagittal spinal alignment. Spine (Phila Pa 1976) 2000; 25:2204-9.

25. Elgafy H, Bransford R, Semaan H, Wagner T. Clinical and radiographic evaluation of sagittal imbalance: a new radiographic assessment. Am J Orthop (Belle Mead NJ) 2011;40:E30-4.

26. Melton LJ 3rd. The prevalence of osteoporosis: gender and racial comparison. Calcif Tissue Int 2001;69:17981.

27. Barrey C, Roussouly P, Perrin G, Le Huec JC. Sagittal balance disorders in severe degenerative spine. Can we identify the compensatory mechanisms? Eur Spine J 2011;20 Suppl 5:626-33. 